Original Research Article

\title{
Comparative evaluation of efficacy and safety of methotrexate either alone or in combination with hydroxychloroquine in patients suffering from rheumatoid arthritis
}

\author{
Amanjot Kaur, Shakti B. Dutta, Amandeep Singh, Amit Varma, Mirza A. Beg*, Subhash Vishal
}

\begin{abstract}
Department of Pharmacology, Shri Guru Ram Rai Institute of Medical and Health Sciences (SGRRIM \& HS), Patel Nagar, Dehradun, Uttarakhand, India
\end{abstract}

Received: 25 May 2017

Accepted: 24 June 2017

*Correspondence to:

Dr. Mirza A. Beg,

Email: mabeg1997@gmail.com

Copyright: (C) the author(s), publisher and licensee Medip Academy. This is an openaccess article distributed under the terms of the Creative Commons Attribution NonCommercial License, which permits unrestricted noncommercial use, distribution, and reproduction in any medium, provided the original work is properly cited.

\begin{abstract}
Background: Rheumatoid arthritis (RA) a chronic autoimmune inflammatory disease and Methotrexate being widely used as monotherapy and in combination for the treatment of RA. Combination therapy provides additional or even more potentiating effects, therefore have been widely used. This study is aimed at comparing the efficacy and safety of Methotrexate either alone or in combination. Methods: This study was conducted for one year from $1^{\text {st }}$ January to $31^{\text {st }}$ December 2015. 52 patients diagnosed with RA were included in this study and were divided in two groups, Group-1 $(n=29)$ patients received methotrexate (MTX) 7.5-15mg/week and Group-2 $(n=23)$ patients received methotrexate $7.5 \mathrm{mg}$ once a week + Hydroxychloroquine (HCQ) 200mg twice daily. The patients were followed up for a period of 16 weeks. Statistical analysis was done by using graph pad insta and $\mathrm{p}$ value of $<0.05$ was considered significant.

Results: A total of 52 patients were included in the study. The mean age of patients was $50.53 \pm 14.81$ years. $43(82.69 \%)$ patients were females and 9 $(17.30 \%)$ were males. $23(44.23 \%)$ patients had positive family history of the disease. The Rheumatoid factor was positive in $42(80.70 \%)$ and anti-CCP was raised in $50(96.15 \%)$ patients. The RAPID-3 and DAS-28 scores on intragroup comparison was highly significant $(\mathrm{p}<0.0001)$ and the intergroup comparison was significant $(p<0.01)$ between baseline and 16 weeks in both the groups. The improvement in inflammatory marker CRP was highly significant on intragroup $(\mathrm{p}<0.0001)$ and intergroup $(\mathrm{p}<0.001)$ comparison between baseline and 16 weeks in both the groups. The mean changes in Vitamin-D3 between baseline and at 16 weeks were insignificant $(\mathrm{p}>0.05)$ in both the groups. Total of Adverse drug reactions reported were $42(50.60 \%)$ in group-1 and $41(49.40 \%)$ in group-2.

Conclusions: The combination therapy was found to be more efficacious than MTX monotherapy in improving symptoms and quality of life. The adverse drug reactions were mild, more in combination therapy and none of the patients required withdrawal of treatment.
\end{abstract}

Keywords: DAS-28, Rheumatoid arthritis, RAPID-3

\section{INTRODUCTION}

The RA is a chronic, progressive inflammatory disease of the synovial lining of the peripheral joints marked by a symmetric peripheral polyarthritis and a wide spectrum of extra-articular features. ${ }^{1}$ The incidence of RA increases between 25 and 55 years of age, after which plateaus until the age of 75 years and then decreases. RA is more common among females than in males in the ratio of 2-3:1. RA affects approximately $0.5-1 \%$ of the population worldwide. Many studies from Africa and Asia show lower prevalence rates for RA in the range of $0.2-0.4 \% .^{2,3}$ The disease results from complex interplay of genetic, environmental and immunologic factors that produce disregulation of the immune system. The early symptoms of the disease are non-specific and patient may present with the constitutional symptoms as weight loss, fatigue, malaise and depression. 
RA has significant negative impact on the ability to perform the daily activities, including work and threshold tasks and health related quality of life. Clinical diagnosis is based on the clinical symptoms and signs with laboratory and radiographic results. The different clinical assessment tools as Disease activity score in 28 joints (DAS-28), Routine assessment of patient index data (RAPID-3), simplified disease activity index (SDAI), clinical disease activity index (CDAI) were designed for use in clinical practice. ${ }^{4}$ Disease activity can be assessed by using clinical laboratory variables as C-reactive protein (CRP), Erythrocyte sedimentation rate (ESR), Rheumatoid factor, Anti-ccp. The more aggressive treatment of RA with disease modifying anti-rheumatic drugs (DMARDs) is to control disease activity, reduce joint erosion and improve quality of life. ${ }^{5}$ Methotrexate is the most widely used DMARD in patients with RA either alone or in combination with other DMARDs and newer biological agents. Hydroxychloroquine being widely used as DMARD agent in RA. Keeping this in view, the present study was conducted to assess the efficacy and safety of methotrexate either alone or in combination with hydroxychloroquine in patients with RA.

\section{METHODS}

The present study was conducted by the Department of Pharmacology in the Medicine OPD for the duration of 1 year from $1^{\text {st }}$ January 2015 to $31^{\text {st }}$ December 2015 . The study was approved by the Institutional Ethics Committee. The written informed consent was taken from the patient/legal guardian. Patients were divided into two groups as group $1(n=29)$ received methotrexate 7.5$15 \mathrm{mg} /$ week and group $2(\mathrm{n}=23)$ received methotrexate $7.5 \mathrm{mg}$ once a week plus hydroxychloroquine $200 \mathrm{mg}$ twice daily. The patients were followed every two weeks till one month and then every 4 weekly for 16 weeks. Scales used for clinical assessment and improvement in quality of life were disease activity score in 28 joints (DAS-28) and Routine assessment of patient index data-3 (RAPID-3) at baseline and at 16 weeks. Lab parameters as rheumatoid factor, anti-cyclic citrullinated peptide antibody (anti$\mathrm{CCP}), \mathrm{C}$-reactive protein (CRP) and Vitamin-D3 were assessed. Adverse drug reaction monitored at each follow up visit. Graph pad insta was used for statistical analysis and $p$ value $(<0.05)$ was considered statistically significant. The intragroup comparison was done using paired t test and intergroup comparison was done by using ANOVA analysis.

\section{RESULTS}

A total of 52 patients were included in the study. 43 $(82.69 \%)$ were females and $9(17.30 \%)$ were males. The Mean age of patient was $50.53 \pm 14.81$ years. Age group wise distribution was done, $19(36.53 \%)$ patients were in 50-65 years of age group followed by $16(30.76 \%) 36-50$ years, $9(17.30 \%)>65$ years and $8(15.38 \%) 20-35$ years age group respectively. $33(63.46 \%)$ patients were housewives, $13(25 \%)$ private workers, $5(9.61 \%)$ farmers and $1(1.92 \%)$ was student. $23(44.23 \%)$ patients had positive family history of the disease. The RA factor was positive in $42(80.70 \%)$ and anti-CCP was raised in 50 (96.15\%) patients (Table 1$)$.

Table 1: Demographic profile of the patients.

\begin{tabular}{|c|c|c|}
\hline \multicolumn{2}{|l|}{ Parameters } & Number (\%) \\
\hline \multicolumn{2}{|c|}{ Mean age (years) } & $50.53 \pm 14.81$ \\
\hline & Female:Male & $43(82.69 \%): 9(17.30 \%)$ \\
\hline \multirow{4}{*}{$\begin{array}{l}\text { Age wise } \\
\text { distribution } \\
\text { (years) }\end{array}$} & $20-35$ & $8(15.38 \%)$ \\
\hline & $35-50$ & $16(30.76 \%)$ \\
\hline & $50-65$ & $19(36.53 \%)$ \\
\hline & $>65$ & $9(17.30 \%)$ \\
\hline \multirow{4}{*}{ Profession } & Housewife & $33(63.46 \%)$ \\
\hline & $\begin{array}{l}\text { Private } \\
\text { workers }\end{array}$ & $13(25 \%)$ \\
\hline & Farmers & $5(9.61 \%)$ \\
\hline & Student & $1(1.92 \%)$ \\
\hline \multicolumn{2}{|c|}{ Positive family history } & $23(44.23 \%)$ \\
\hline \multicolumn{2}{|c|}{ Positive RA Factor } & $42(80.70 \%)$ \\
\hline \multicolumn{2}{|c|}{ Raised Anti-CCP } & $50(96.15 \%)$ \\
\hline
\end{tabular}

The routine assessment of patient index data-3 (RAPID-3) scores were $3.67 \pm 0.06$ and $3.79 \pm 0.09$ in group 1 and 2 at baseline and $2.65 \pm 0.09$ and $2.13 \pm 0.15$ in group 1 and 2 at 16 weeks respectively. The intragroup comparison at baseline and 16 weeks was highly significant $(\mathrm{p}<0.0001)$ and the intergroup comparison was significant $(\mathrm{p}<0.01)$ (Figure 1).

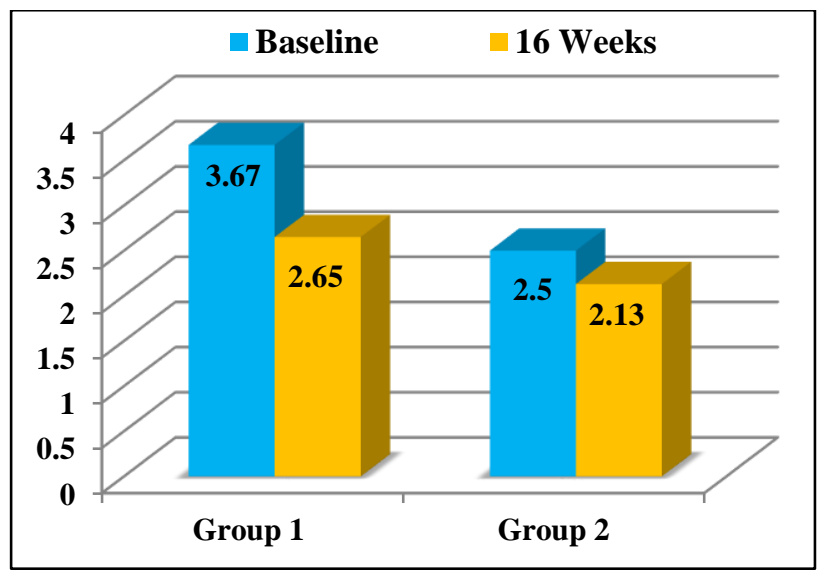

Intragroup and intergroup comparison $\mathrm{p}$ value $<0.0001$ and $<0.001$ respectively.

\section{Figure 1: Changes in RAPID-3 score at baseline and} at 16 weeks.

The disease activity score-28 were $3.96 \pm 0.12$ and $4.39 \pm 0.14$ in group 1 and 2 at baseline respectively and $3.20 \pm 0.12$ and $2.53 \pm 0.11$ in group 1 and 2 at 16 weeks respectively. The intragroup comparison was highly significant $(p<0.0001)$ in group 1 and group 2 . The intergroup comparison was significant in group 1 and group $2(\mathrm{p}<0.001)$ (Figure 2$)$. 


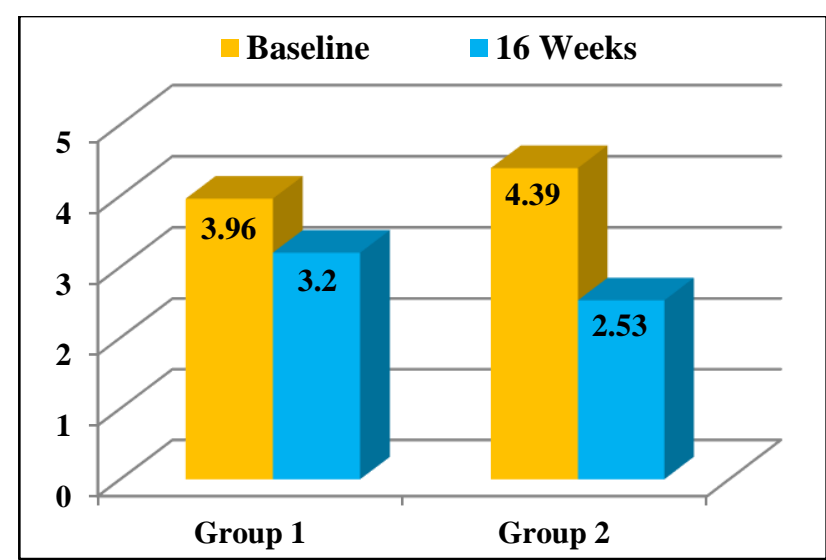

Intragroup and intergroup comparison $\mathrm{p}$ value $<0.0001$ and $<0.001$ respectively.

Figure 2: Changes in DAS-28 at baseline and 16 weeks.

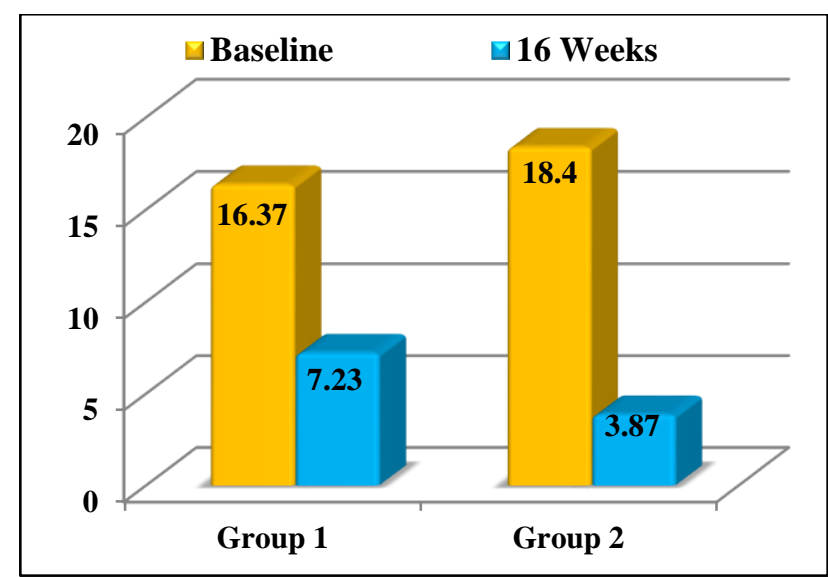

Intragroup and intergroup comparison $\mathrm{p}$ value $<0.0001$ and $<0.001$ respectively.

Figure 3: Changes in CRP at baseline and at 16 weeks.

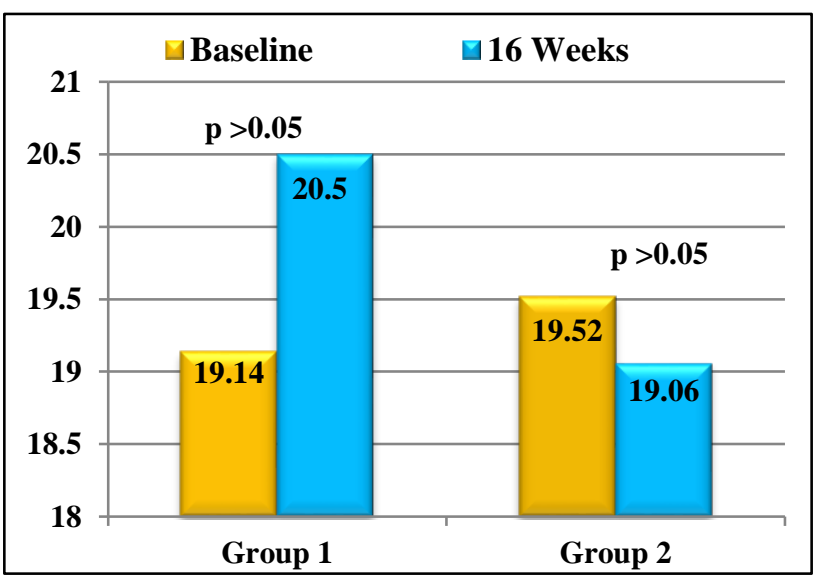

Figure 4: Changes in Vitamin D3 at baseline and 16 weeks.

The C Reactive protein (CRP) level was $16.37 \pm 0.91$ and $7.23 \pm 0.53$ at baseline and 16 weeks in group 1 and the improvement was highly significant ( $\mathrm{p}<0.0001)$. The CRP level was $18.40 \pm 1.42$ at baseline and $3.87 \pm 0.40$ at 16 weeks in group 2 and the improvement was highly significant ( $\mathrm{p}<0.0001)$. The intergroup comparison between group 1 and 2 was significant ( $\mathrm{p}<0.001$ ) (Figure $3)$.

The mean value of Vitamin D3 was $19.14 \pm 0.42$ and $20.5 \pm 0.86$ at baseline and 16 weeks respectively in group 1. The mean value of Vitamin D3 was $19.52 \pm 0.98$ and $19.06 \pm 1.8$ at baseline and 16 weeks respectively in group 2. The intragroup comparison at baseline and 16 weeks was not significant ( $p>0.05$ ) in both the groups (Figure 4$)$. Total ADRs reported were $42(50.60 \%)$ in group 1 and 41 $(49.40 \%)$ in group 2 (Table 2). All the values were expressed in Mean \pm SEM.

Table 2: Adverse drug reactions over the study period.

\begin{tabular}{|lll|}
\hline ADRs (83) & Group 1 & Group 2 \\
\hline Nausea & $4(4.81 \%)$ & $7(8.43 \%)$ \\
\hline Vomiting & $2(2.40 \%)$ & $4(4.82 \%)$ \\
\hline Epigastric pain & $4(4.81 \%)$ & $7(8.43 \%)$ \\
\hline Bloating sensation & $9(10.84 \%)$ & $6(7.23 \%)$ \\
\hline Generalized body pain & $6(7.23 \%)$ & - \\
\hline Diarrhea & $1(1.20 \%)$ & $3(3.61 \%)$ \\
\hline Hair fall & - & $1(1.20 \%)$ \\
\hline Constipation & $6(7.23 \%)$ & - \\
\hline Loose stools & $3(3.61 \%)$ & - \\
\hline Hyper pigmentation of lips & $1(1.20 \%)$ & $1(1.20 \%)$ \\
\hline Mouth ulcers & $6(7.23 \%)$ & $10(12.04 \%)$ \\
\hline Hoarseness of voice & - & $1(1.20 \%)$ \\
\hline Dry cough & - & $1(1.20 \%)$ \\
\hline
\end{tabular}

\section{DISCUSSION}

Rheumatoid arthritis (RA) is a chronic, progressive, inflammatory disease of the synovial lining of peripheral joints. The early treatment with DMARDs could improve disease activity, reduce joint erosion and delay joint damage. Methotrexate is the most commonly used DMARD alone or in combination with other drugs for RA. Thus, with this view the present study was conducted to assess the efficacy and safety of most commonly used DMARD Methotrexate either alone or in combination with Hydroxychloroquine.

The mean age in our study was 50.53 years which was in collaboration with the previous studies by Bajraktari IH et al, and Lee EB et al, where mean age of the patients were 51.30 and 48.80 years respectively. ${ }^{6,7}$ In present study the females outnumber the males this is similar to previous studies which showed high prevalence of RA among females than males. ${ }^{6-9}$ Our study showed $44.23 \%$ patients had positive family history and this finding is similar to the case control study by Koumantaki Y et al, which suggests significant association of developing RA among first degree relatives. ${ }^{9} 63.46 \%$ of the affected patients were housewives which is in contrast to the earlier study by 
Bajraktari IH et al, where the largest proportion of affected patients were farmers (38\%) followed by housewives $32.2 \% .^{6}$ In the present study the RA factor was positive in $80.70 \%$ of the patients which is in accordance with the study by Lee EB et al, which showed higher percentage of positive RA factor $(84.4 \%) .^{7}$ The anti-CCP was raised in $96.15 \%$ of the patients while in another study by Lee EB et al showed Anti-CCP levels were raised in $86.6 \%$ of patients. ${ }^{7}$

In our study the mean changes in Disease Activity Score in 28 joints (DAS-28) has shown decrease by -0.76 in group 1 over the duration of 4 months, whereas in another study by Lee EB et al, showed improvement in DAS-28 by -1.9 during study period of 6 months by using methotrexate alone at a dose that was increased to $20 \mathrm{mg}$ once a week. ${ }^{7}$ In group 2 the DAS- 28 score has reduced by -1.86 over 4 months and the study by Mathur $\mathrm{R}$ et al, showed improvement in disease activity score by -1.02 at 4 weeks by combination of methotrexate at a dose of $7.5 \mathrm{mg}$ to $25 \mathrm{mg}$ once a week and Hydroxychloroquine at 200mg twice daily. ${ }^{10}$

A study by Song Y et al, on RA has shown that clinical disease activity as assessed by Routine Assessment of Patient Index Data (RAPID) improved quality of life by improving physical function, pain and global health status. ${ }^{11}$ In the present study the RAPID-3 score has been found to be decreased at 16 weeks by -1.02 (from $3.67 \pm 0.06$ at baseline to $2.65 \pm 0.09$ at 16 weeks), 1.66 (from $3.79 \pm 0.09$ at baseline to $2.13 \pm 0.15$ at 16 weeks) in group 1, group 2 respectively. In the study by Pincus $\mathrm{T}$ et al, RAPID-3 score was found to be effective as a guide to assess continuous quality of life. ${ }^{12}$

A significant improvement in the C-reactive protein was observed in both the groups between baseline and 16 weeks, which is in accordance with the earlier study by Lipsky PE et al. ${ }^{13}$ The mean changes in Vitamin-D3 level from baseline to 16 weeks were not significant $(p>0.05)$ in both the groups. These findings are similar to the study by Rossini M et al. ${ }^{14}$ The vitamin-D deficiency is found to be common in RA patients and Greater intake of Vitamin$\mathrm{D}$ is found to be inversely related to the risk of RA. ${ }^{15}$ In the present study the patients were not prescribed Vitamin-D3 to RA patients.

Drugs were well tolerated and none of the patients withdraw due to the side effects. The ADRs reported in the present study were $67.47 \%$ gastrointestinal, $19.28 \%$ were mouth ulcers, $7.23 \%$ were generalized body pain and $2.41 \%$ were hyperpigmentation of lips and similar ADRs have been reported in the previous studies by Bathon JM et al, which also reported the occurrence of nausea (29\%), diarrhea (12\%), abdominal pain (10\%) and mouth ulcers (14\%) with the use of methotrexate. ${ }^{16}$ The ADRs reported in group 2 were $60 \%$ gastrointestinal distress, $22.22 \%$ mouth ulcers, $8.88 \%$ were decrease in vision and $8.88 \%$ others. This is similar to the study by O'Dell JR et al, also reported the gastrointestinal side effects in patients taking methotrexate and Hydroxychloroquine in combination therapy in the study period of two years. ${ }^{17}$

\section{Limitations}

The patients and doctors were aware of the prescribed drugs and hence more chances of errors. The sample size was small which may not be sufficient enough to demonstrate the intergroup difference in efficacy of study drugs. Longer duration of follow up with larger sample size needed to further evaluate the efficacy and safety of DMARDs.

Funding: No funding sources

Conflict of interest: None declared

Ethical approval: The study was approved by the Institutional Ethics Committee

\section{REFERENCES}

1. Helmick CG, Felson DT, Lawrence RC, Gabriel S, Hirsch R, Kwoh CK et al. Estimates of the prevalence of arthritis and other rheumatic conditions in the united states. Arthritis Rheum. 2008;58:15-25.

2. Shah A, St. Clair EW. Rheumatoid Arthritis. In Longo DL, Fauci, Kasper DL, Hauser SL, Jameson JL, Loscalzo J. Harrison's Principles of Internal Medicine. $18^{\text {th }}$ Edition, Mc Graw Hill; 2012:2738-2752.

3. Symmons DM, Barrett EM, Bankhead CR, Scott DI, Silman AJ. The occurrence or rheumatoid arthritis in the United Kingdom: results from the Norflok Arthritis Register. Br J Rheumatol. 1994;33:735-79.

4. Aletaha D, Smolen J. The Simplified Disease Activity Index (SDAI) and the Clinical Disease Activity Index (CDAI): a review of their usefulness and validity in rheumatoid arthritis. Clin Exp Rheumatol. 2005;23:S100-8.

5. Choi HK, Hernán MA, Seeger JD, Robins JM, Wolfe F. Methotrexate and mortality in patients with rheumatoid arthritis: a prospective study. The Lancet. 2002 Apr 6;359(9313):1173-7.

6. Bajrakatri IH, Cico TB, Meka VS, Bajrataki H, Saiti V, Krasniqi B et al. Demographic Features of patients with rheumatoid arthritis in Kosovo. Med Arh. 2014;68(6):407-10.

7. Lee EB, Fleischmann R, Hall S, Wilkinson B, Bradley JD, Gruben D, et al. Tofacitinib versus methotrexate in rheumatoid arthritis. NEJM. 2014;370:2377-86.

8. O' Dell JR, Mikuls TR, Taylor TH, Ahluwalia V, Brophy M, Warren SR, et al. Therapies for active rheumatoid arthritis after methotrexate failure. NEJM 2013;369:307-18.

9. Koumantaki Y, Giziaki E, Linos A, Kontomerkos A, Kaklamanis P, Vaiopoulous G, et al. Family History as a risk factor for rheumatoid arthritis. J Rheumatol. 1997;24(8):1522-6.

10. Mathur R, Singh H, Arya S, Singh V. Comparative evaluation of efficacy of Leflunomide versus combination of methotrexate and hydroxychloroquine 
in patients with Rheumatoid Arthritis. Indian Journal of Rheumatology. 2016 ;11(2): 86-90.

11. Song Y, Li-an Zhu, Wang SL, Leng L, Bucala R, Lu LG. Multi dimensional Health Assessment Questionnaire in China: Reliability, Validity and Clinical Value in Patients with Rheumatoid Arthritis. 2014;9(5):1-9.

12. Pincus T, Callahan LF, Sale WG, Brooks AL, Payne LE, Vaughn WK. Severe functional declines, work disability, and increased mortality in seventy-five rheumatoid arthritis patients studied over nine years. Arthritis Rheum. 1984;27:864-72.

13. Lipsky PE, Desiree MFM, Heijde VD, St. Clair W, Daniel E, Ferdinand $\mathrm{C}$, et al. Infliximab and Methotrexate in the treatment of rheumatoid arthritis. NEJM. 2000;343:1594-602.

14. Rossini M, Bongi SM, Montanga GL, Minisola G, Malavolta N, Berini L, et al. Vitamin D deficiency in rheumatoid arthritis: Prevalence, determinants and associations with disease activity and disability. Arthritis research and therapy. 2010;12(216):2-7.
15. Linda AM, Curtis J, Mikuls TR, Cerhan JR, Criswell LA, Saag KG. Vitamin D is inversely associated with Rheumatoid Arthritis. Arthritis and Rheumatism. 2004;50(1):72-7.

16. Bathon JM, Marthin RW, Fleischmann RM, Tesser JR, Keystone E, Schiff MH, et al. A comparison of Etanercept and Methotrexate in patients with early rheumatoid arthritis. NEJM. 2000;343(22):1586-93.

17. O'Dell JR, Claire E, Haire RN, Erikson N, Drymalski $\mathrm{W}$, Plamer W, et al. Treatment of rheumatoid arthritis with methotrexate alone, Sulfasalazine and hydroxychloroquine, or a combination of all three medications. NEJM. 1996;334:1287-91.

Cite this article as: Kaur A, Dutta SB, Singh A, Varma A, Beg MA, Subhash V. Comparative evaluation of efficacy and safety of methotrexate either alone or in combination with hydroxychloroquine in patients suffering from rheumatoid arthritis. Int J Basic Clin Pharmacol 2017;6:1996-2000. 